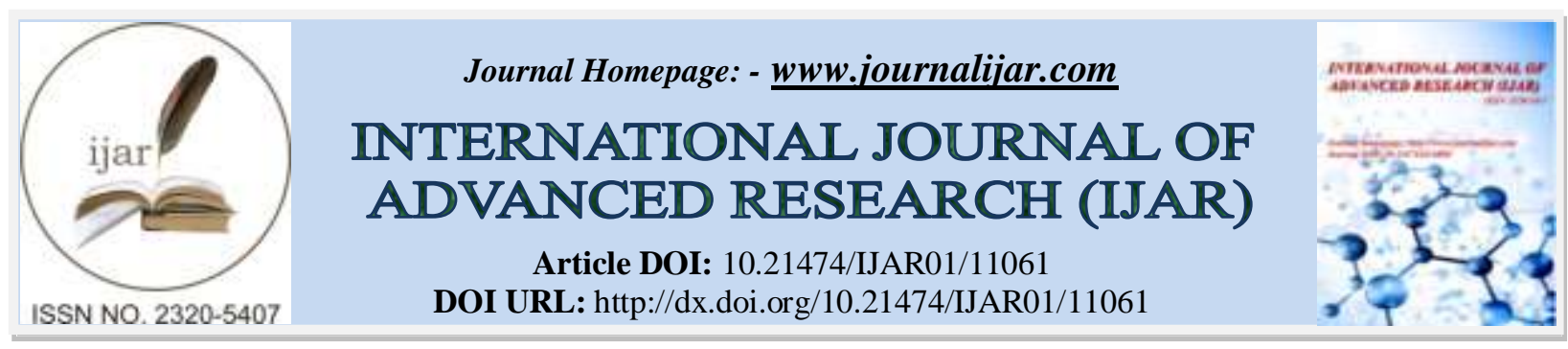

RESEARCH ARTICLE

\title{
EXTRACTION OF BIOETHANOL FROM PRETREATED SAWDUST
}

Ajah Chinonye Peace, Dr. Akujobi Campbell and Dr. Wesley Braide

Department of Microbiology, Federal University of Technology Owerri, Imo State. PMB 1526.

\section{Manuscript Info}

Manuscript History

Received: 01 April 2020

Final Accepted: 05 May 2020

Published: June 2020

Key words:-

Box behnken, Brix, Enzyme hydrolysis,

Pre-treatment, Response Surface Methodology (RSM)

\begin{abstract}
In this study, optimization of brix conversion of wood shavings by Saccharomyces cerevisiae was investigated. Wood shavings were collected from timber shade at Naze, Owerri Imo state. Chemical pretreatment and hydrolysis was evaluated. Brewer's yeast (Saccharomyces cerevisiae) was used as the isolate for fermentation. A five factor box behnken design was used. The effect of incubation temperature $(30-40 \circ \mathrm{oC})$, inoculum size $(0.85)$,incubation time (72120hours), wood concentration( $10-20 \mathrm{~g}$ ), and $\mathrm{NaOH}$ concentration (3.5-4.5\%) were studied using response surface methodology (RSM). Brix concentration was used as a response in the resulting experimental design. The statistical analysis of the constructed model developed by RSM suggested that linear effects of $\mathrm{NaOH}$ concentration and wood concentration were both significant $(\mathrm{p}<0.05)$ for biomass converted. The optimum conditions for the conversion of brix are wood concentration of $15.66 \mathrm{~g}, \mathrm{NaOH}$ concentration of $4.47 \%$, inoculum size of 0.85 , incubation time of 72 hours and incubation temperature of $40 \mathrm{oC}$. Ethanol yield obtained was $1.68-2.25 \%$. At these conditions, the isolate used was able to convert $60.97 \%$ of the brix in the wood extract to ethanol.
\end{abstract}

Copy Right, IJAR, 2020,. All rights reserved.

\section{Introduction:-}

Bioethanol is ethanol derived from the process of fermentation of biological materials. This is accomplished by the action of microorganism like yeast. Since the microorganism utilizes only simple sugars, starchy and cellulosic materials are first converted into simple sugars by a process of hydrolysis before they are subjected to fermentation. According to (Rob, 2008), the worldwide production of cellulosic ethanol will amount to at least 16.5 billion gallons in 2020, if the target set in the United States, China, Europe, Japan and Brazil are achieved. Based on currently proposed and signed legislation, the United States would account for over $63.9 \%$ of that market, while the EU and China would account for $10.4 \%$ and $11.5 \%$ respectively. Although Brazil does not have any official legislation on cellulosic ethanol, it is included based on its market penetration, which amount to around 2.1 billion gallons (12.9\%) in 2020. Ethanol is generally produced from the fermentation of sugars. First generation processes typically rely on yeasts that convert six-carbon sugars (mainly glucose) to ethanol (and carbon dioxide). Starch is easily converted to sugar by acid or enzyme hydrolysis. The organisms and enzymes required for starch conversion and glucose fermentation on a commercial scale are readily available. The conversion of cellulose to sugar is more complicated due to the presence of lignin and because cellulose is usually converted into both five and six carbon sugars (pentose and hexose, respectively) which require more sophisticated organisms for fermentation (Rob, 2008).

Corresponding Author:- Ajah. C., Dr. Wesley Braide Address:- Department of Microbiology, Federal University of Technology Owerri, Imo State. PMB 
Cellulosic ethanol, ethanol from forestry or agricultural waste is considered a way to prevent displacement of crops to feed humans. Corn-basedethanol has been blamed by some for higher food prices and shortages because food producers are attimes forced to compete with energy companies for grain. Some also argue that the growing demand for such crops is also responsible for indirect land-use change, the destruction of rain forest and wetlands to make room for more farmland. It has been shown that cellulosic ethanol is a viable alternative for reducing oil dependences while protecting food crops. Corn-Stover and switch grass are very potential cellulosic feed (Stock Gallagher,(2003), also stated that crop residues are likely the lowest cost biomass source.

\section{Materials And Methods:-}

The cellulosic material used in the experiment to produce Bioethanol were obtained from timber market (sawmill) located at Naze, Owerri Imo state. The other materials were $100 \mathrm{~g}$ of wood sawdust , $2 \%$, 3\% and 4\% concentration)of Tetra-oxo-sulphate (6) acid, 2\%, 3\% and 4\% of sodium hydroxide, packages of brewers yeast (EBY 100 strain), distilled water, test tubes, $250 \mathrm{~mL}$ conical flask, measuring cylinders, glass bioreactor, refractometer, $\mathrm{pH}$ conductivity meter, incubator, whatman filter paper, water bath, incubator, autoclave, spectrophotometer and electronic balance.

\section{Cellulose hydrolysis}

$15 \mathrm{~g}$ of wood shavings (substrate A) was measured into 3 conical flasks each containing $2 \%, 3 \%$ and $4 \%$ sulphuric acid. Also, 15g of wood shavings (substrate B) was measured into 3 conical flasks each containing 2\%, 3\%, and $4 \%$ sodium hydroxide. All six (6) conical flasks were heated at $1000 \mathrm{C}$ for $30-40$ minutes after pretreatment to remove impurities. They were allowed to cool and filtered afterwards using the whatman filter paper.

\section{Determination of Brix level.}

The Brix level were determined for all six flask using a refractometer.

\section{Multiplication/standardization of the isolate (yeast)}

$10 \%$ glucose was prepared and the yeast was inoculated into it and incubated aerobically for 48hours to multiply the yeast. After incubation, the isolate were made in triplicates using a turbidity scale of 4,5 and 6 respectively and the optical densities were standardized using the Mc farlands standard table with the aid of a spectrophotometer at $600 \mathrm{~nm}$.

After hydrolysis, the $\mathrm{pH}$ was reduced to a proper level of within 6.5-7.0 with distilled water using a $\mathrm{pH}$ conductivity meter. Then the products from the $\mathrm{pH}$ normalization were inoculated with yeast for fermentation to proceed.

\section{Balancing optical densities.}

Using McFarland's standard, the optical densities of the 46 extracts were balanced respectively.

\section{Fermentation of hydrolyzed sawdust.}

Fifteen mililitre of the yeast were inoculated into the $250 \mathrm{ml}$ conical flask for the whole forty six (46) extracts and incubated at a temperature of $30 \mathrm{oC}, 35 \mathrm{oC}$, and $40 \mathrm{oC}$ respectively for 72 hours, 90 hours, 120 hours.....

\section{Optimization study}

The Bohx benken design was adopted for the optimization of the production of Bioethanol in a $5 \times 3$ design, that is, five factors in three levels using Minitab (Design of Experiment). Factors include Temperature (30, 35 and 40 degrees), Time of incubation (72, 96 and 120 Hours), concentration of inoculum (crystal yeast) - $(0.5,0.65,0.85)$, concentration of Alkaline (3.5, 4.0, and 4.5) and substrate concentration $(10,15,20)$.

\section{Statistical Analysis}

Results obtained from this work was subjected to statistical Analysis at $\mathrm{P}<0.05$ using the MINITAB 17 Software to obtain response surface plots, Statistical Significance of Factors as well as interval plots of differences and deviations across the Mean. 


\section{Results And Discussion:-}

Preliminary assessment of hydrolytic property of Acid and Alkaline on Saw dust

Brix levels of hydrolyzed wood, demonstrated by the amount of brix produced in the wood extract was measured and tabulated in Table 3.1. The results show that higher brix was recovered from the alkaline treatment than the Acid treatment.

Table 1:- Brix levels of hydrolyzed wood for alkaline and acid treatment.

\begin{tabular}{lcccc}
\hline Concentration & Brix after Base Potential & \multicolumn{3}{l}{ Brix after Acid Potential } \\
& Hydrolysis & Alcohol Pretreatment & Alcohol \\
$2 \%$ & 3.5 & $1.96 \%$ & 2.2 & $1.23 \%$ \\
\hline $3 \%$ & 5.0 & $2.82 \%$ & 3.4 & $1.91 \%$ \\
$4 \%$ & 6.8 & $3.87 \%$ & 4.8 & $2.71 \%$ \\
\hline
\end{tabular}

\section{Main effects plot for biomass converted.}

The single effects of Wood concentration, sodium hydroxide concentration (NAOH), and inoculum size (OD), incubation time (hrs.), and incubation temperature on the conversion of biomass converted for the production of Bioethanol is shown in Figure 1. The production of bioethanol, characterized by biomass conversion to alcohol, was observed to increase with increase in wood concentration until a concentration of $15 \mathrm{~g} / 100 \mathrm{ml}$ was reached. Above this concentration, there was a considerable decrease in biomass converted. The biomass converted as a result of changes in the wood concentration had significant effects at $p<0.05$.

On the other hand, the effect of $\mathrm{NaOH}$ concentration on the biomass converted was also studied. The results showed that there was a positive correlation between increase in the concentration of $\mathrm{NaOH}$ and Biomass converted until a concentration $>4 \%$. Afterwards biomass converted remained fairly constant with increase in $\mathrm{NaOH}$ concentration.

Similarly, the effect of the increase in $\mathrm{NaOH}$ in relation to Biomass converted was significant at $\mathrm{P}<0.05$. The effect of inoculum size and incubation time on the Biomass converted was also studied. Despite the fact that these two factors had no significant effect at $p<0.05$, results showed that an increase in each of both factors resulted to a slight increase in the biomass converted. Similar result was also recorded for the incubation temperature. A slight decrease in biomass converted was recorded as a result of a slight increase in incubation temperature for up to 380C which was followed by an increase till the end of the experiment. Also, this effect was not significant value at $\mathrm{P}<0.05$.

Fig1:- Main effects plot for biomass converted.

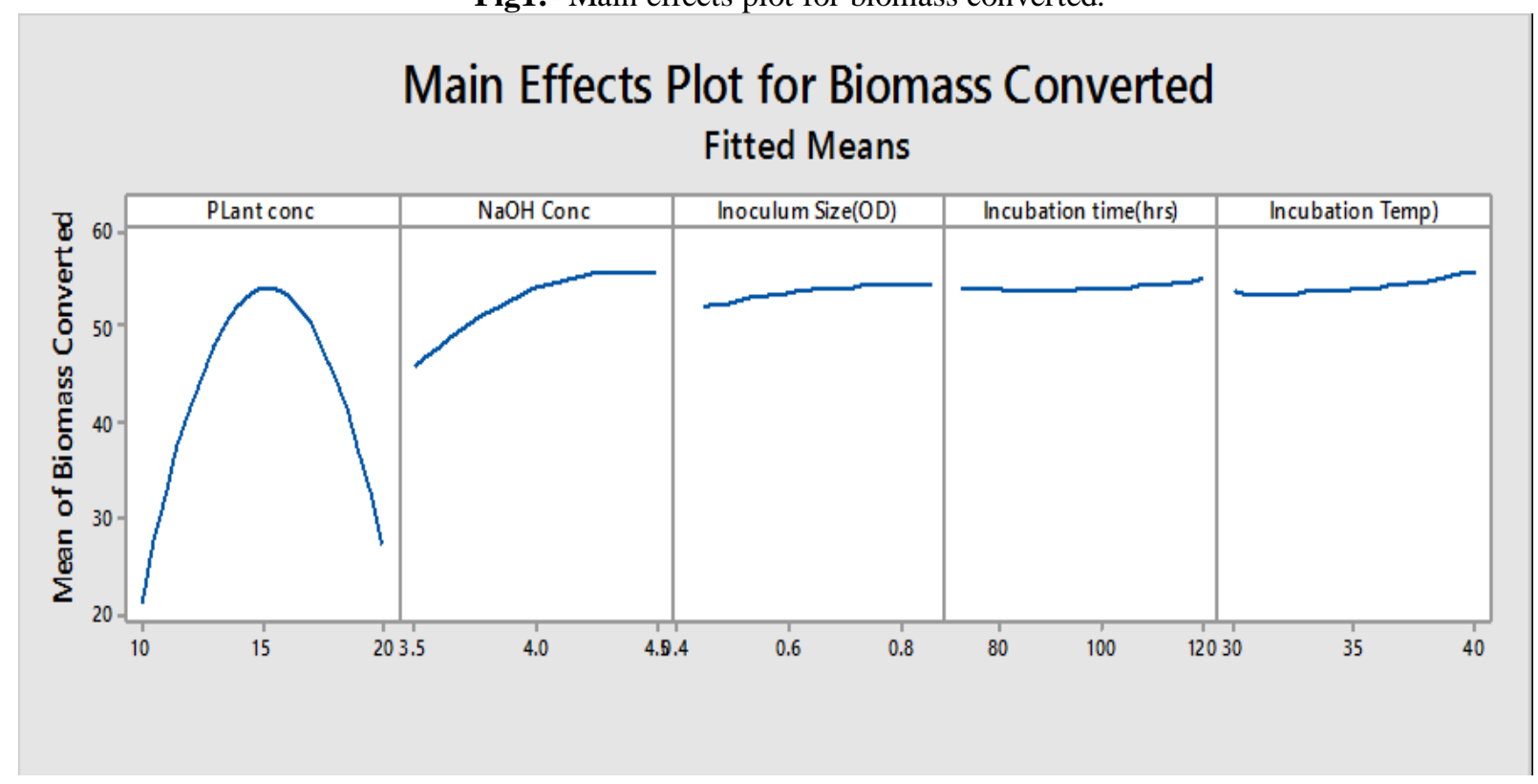




\section{Response surface plots for the interaction of effects in three dimensional diagrams.}

The response surface plots are useful in determining the three dimensional view of all effects as a variable of the biomass converted. It aids in the comprehension of the main effects and interaction plots by analyzing each interaction separately. The response surface plots are shown in figure 2-5.

Fig 2a shows the surface plot of biomass converted vs. incubation temperature and incubation time. At constant holding values of wood concentration, $\mathrm{NAOH}$ concentration, and inoculum size (OD), the biomass converted shows an initial increase with an increase in incubation time, while there was a corresponding increase in biomass with increase in incubation temperature. Despite a favorable cup shaped surface plot indicating a favorable interaction, results of this interaction are not significant at $\mathrm{P}<0.05$.

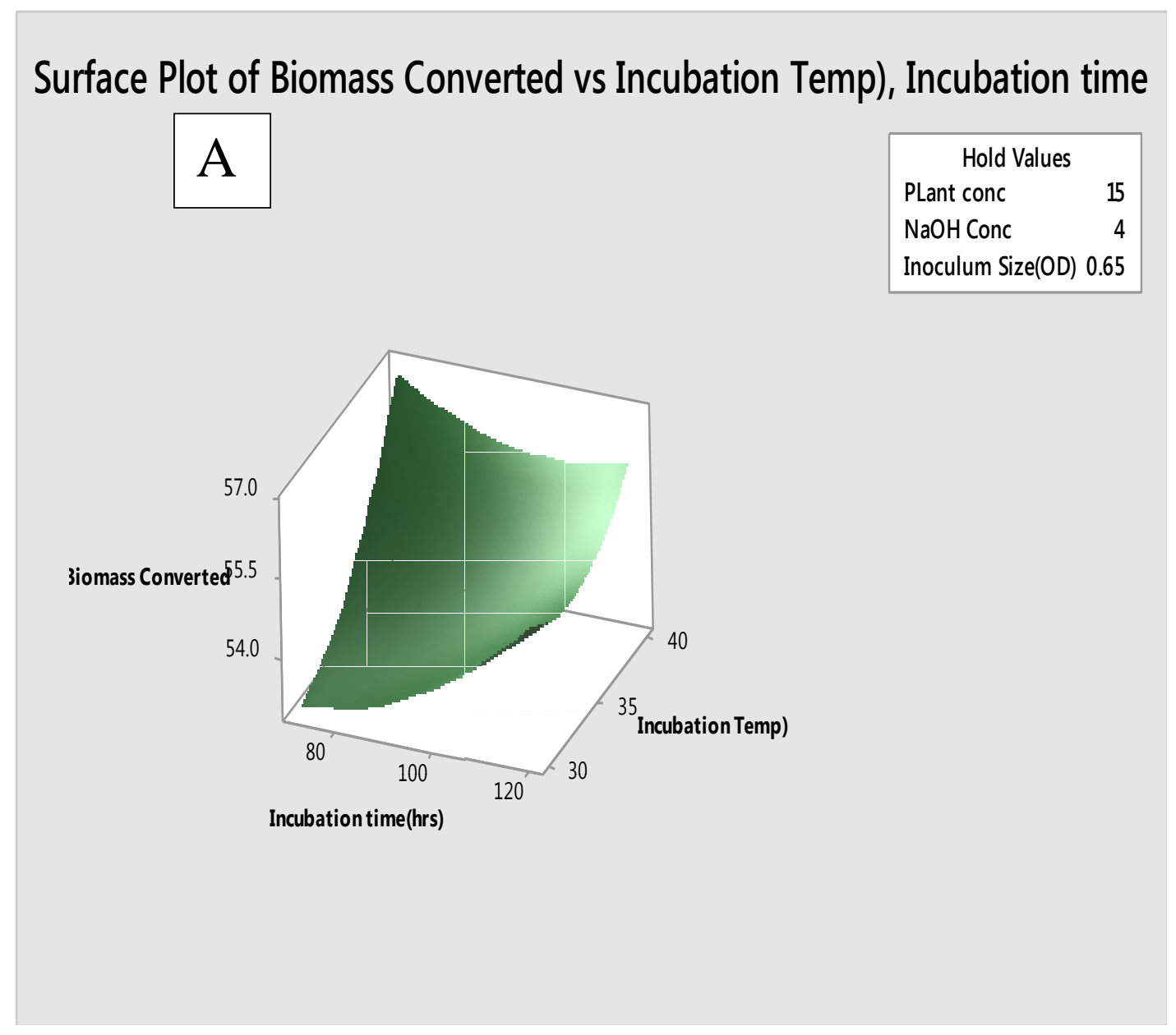

Fig. 2b. Shows a surface plot of biomass converted vs. incubation temperature and inoculum size. Results of the response surface plot shows that at constant holding values of wood concentration, $\mathrm{NaOH}$ concentration and incubation time, the converted biomass increases with an increase in inoculum size up till 0.65 with further increase in infulum size. An increase in biomass converted was recorded as a function of increase in incubation temperature. The interaction is not significant at $\mathrm{P}<0.05$. 


\section{Surface Plot of Biomass Converted vs Incubation Temp), Inoculum Size(0}

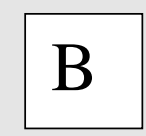

\begin{tabular}{|lr|}
\hline \multicolumn{2}{|c|}{ Hold Values } \\
PLant conc & 15 \\
NaOH Conc & 4 \\
Incubation time(hrs) & 96 \\
\hline
\end{tabular}

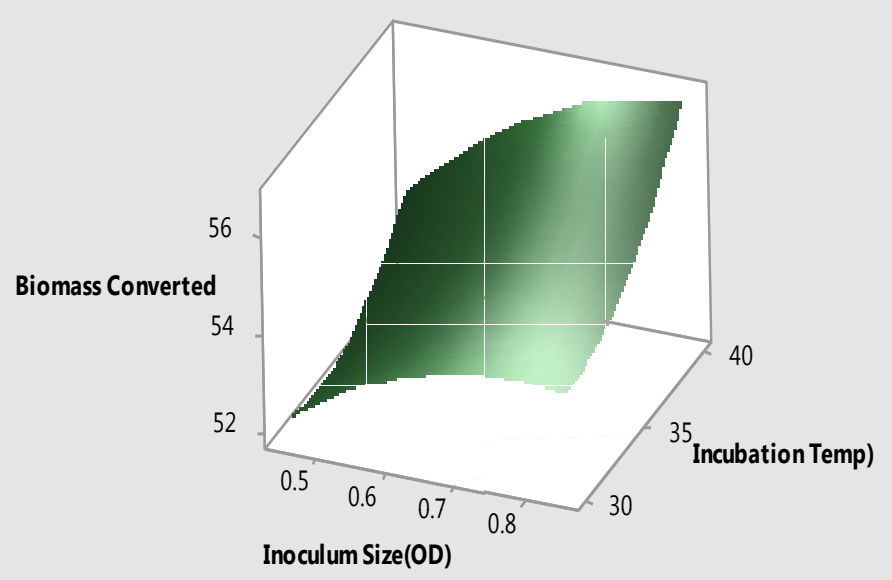

Fig. 2b:- Shows a surface plot of biomass converted vs. incubation temperature and inoculums size.

Results of the response surface plot shows that at constant holding values of wood concentration, $\mathrm{NaOH}$ concentration and incubation time, the converted biomass increases with an increase in inoculum size up till 0.65 with further increase in inoculum size. An increase in biomass converted was recorded as a function of increase in incubation temperature. The interaction is not significant at $\mathrm{P}<0.05$.

Fig. 3a. Shows the surface plot of biomass converted vs. inoculum size and incubation time. At constant holding values of plant concentration, $\mathrm{NaOH}$ concentration, incubation temperature, there was a considerable increase in biomass converted as a result of an increase in inoculum size. However, towards the end of the experiment, the effect of increase in the inoculum size was not resulting to an increase in biomass converted. In addition, an increase in biomass converted was also recorded as a function of an equivalent increase in time of incubation. However, these interacting effect results were not significant at $\mathrm{P}<0.05$. 


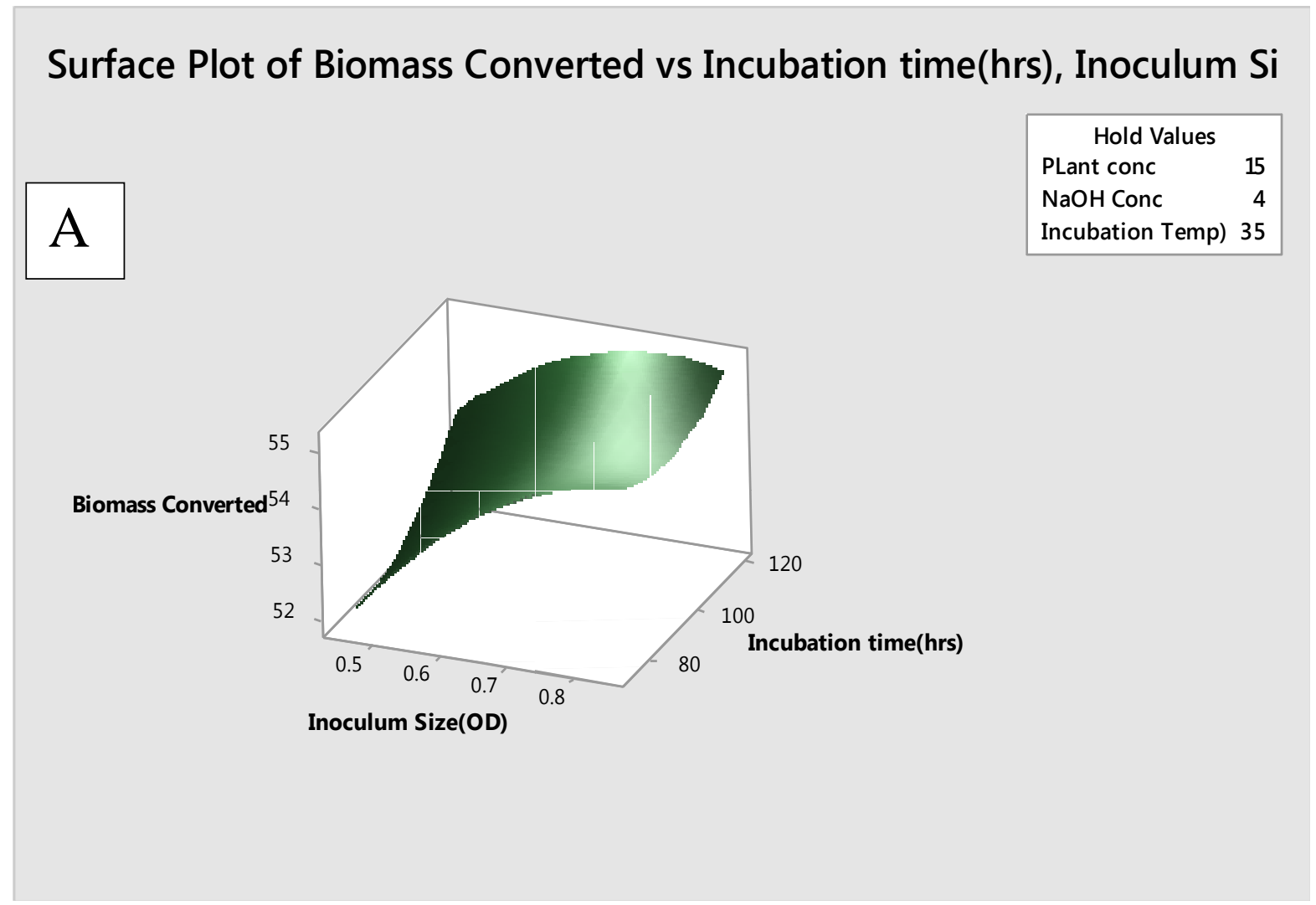

Figure 3a:- Surface plot of Biomass Converted vs. Incubation time, Inoculum size.

Fig. $3 b$ shows that at constant holding values of wood concentration, inoculum size and incubation time, the surface plot shows that the increase in biomass converted was not directly proportional to increase in $\mathrm{NaOH}$ concentration as seen in the figure.an increase in biomass converted showed a corresponding increase in incubation time. However, this result is not significant at $\mathrm{P}<0.05$.

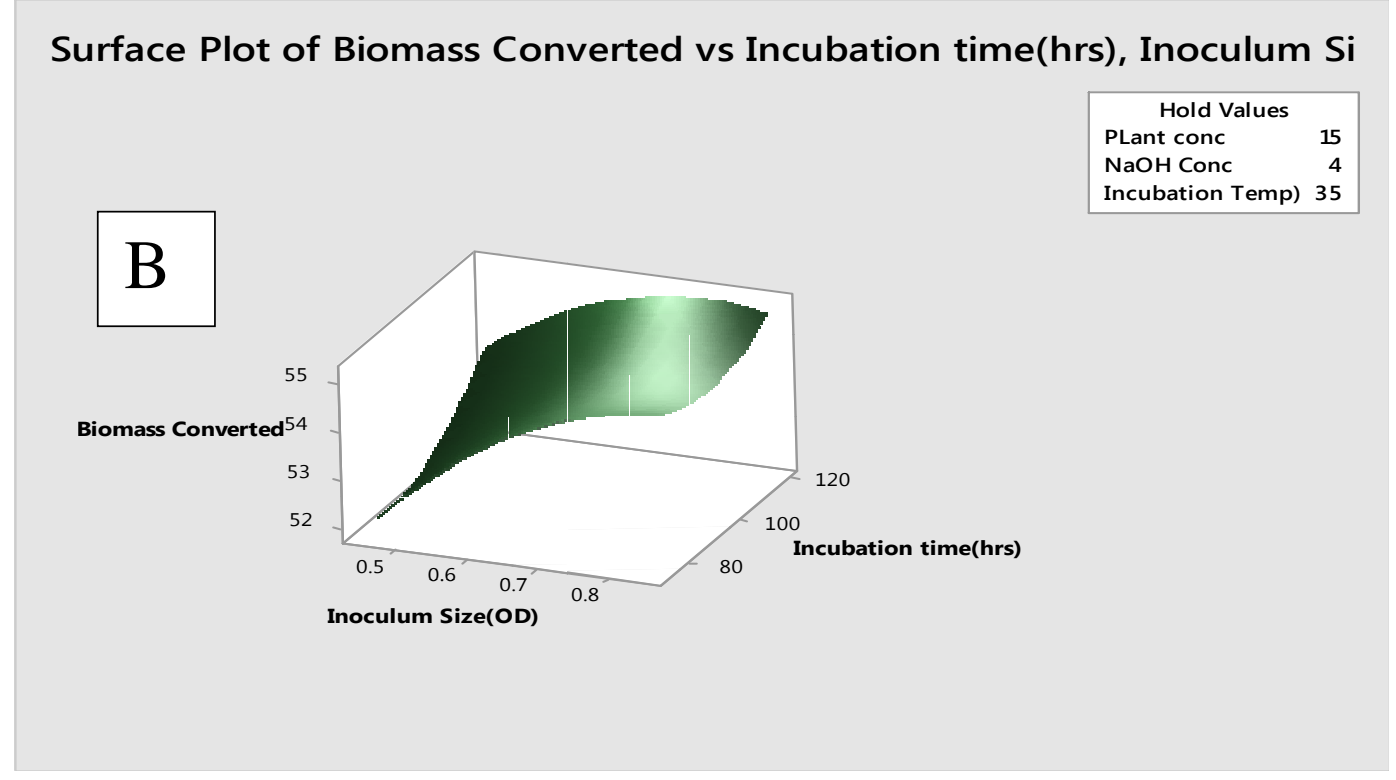

Figure 3(b):- Surface plot of Biomass Converted vs. Incubation Time, Inoculum Size. 
Fig. 4a shows that at constant holding values of wood concentration, inoculum size and incubation time, the surface plot shows that the increase in biomass converted was not directly proportional to increase in $\mathrm{NaOH}$ concentration as seen in the figure. an increase in biomass converted showed a corresponding increase in incubation time. However, this result is not significant at $\mathrm{P}<0.05$.

\section{Surface Plot of Biomass Converted vs Incubation time(hrs), $\mathrm{NaOH}$ Conc}

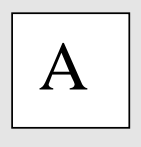

\begin{tabular}{|lr|}
\hline \multicolumn{2}{|c|}{ Hold Values } \\
PLant conc & 15 \\
Inoculum Size(OD) & 0.65 \\
Incubation Temp) & 35 \\
\hline
\end{tabular}

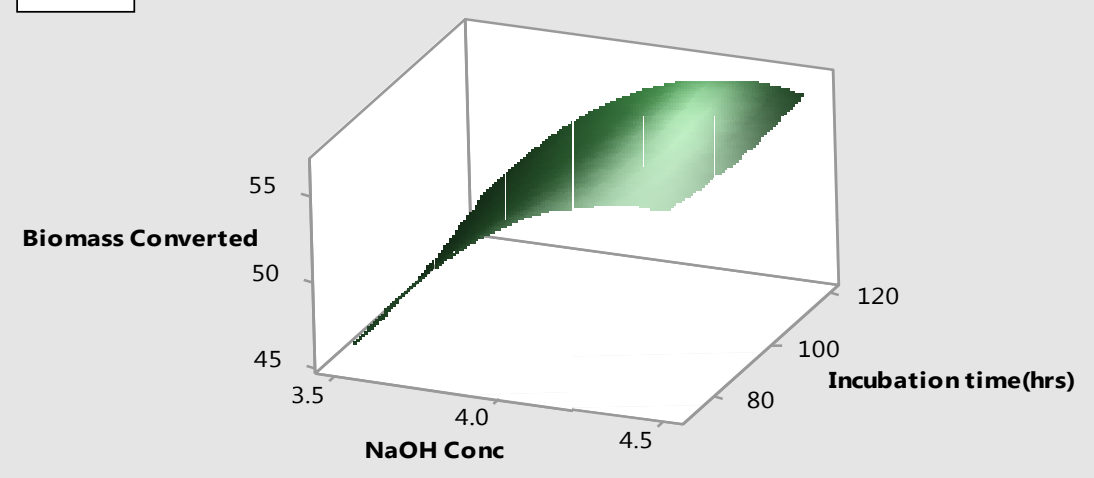

Figure 4a:- Surface Plot of Biomass Converted vs. incubation time, $\mathrm{NaOH}$ Concentration.

Fig. 4b. Represents a surface plot of the interaction of the effects of $\mathrm{NaOH}$ and Inoculum size on Biomass converted. The plots shows that at constant holding values of wood concentration, incubation time, incubation temperature, there was a considerable increase in biomass converted with increase in $\mathrm{NaOH}$ concentration. Similar results was also observed in the inoculum size. However, results are not significant at $\mathrm{P}<0.05$.

\section{Surface Plot of Biomass Converted vs Inoculum Size(OD), NaOH Conc}
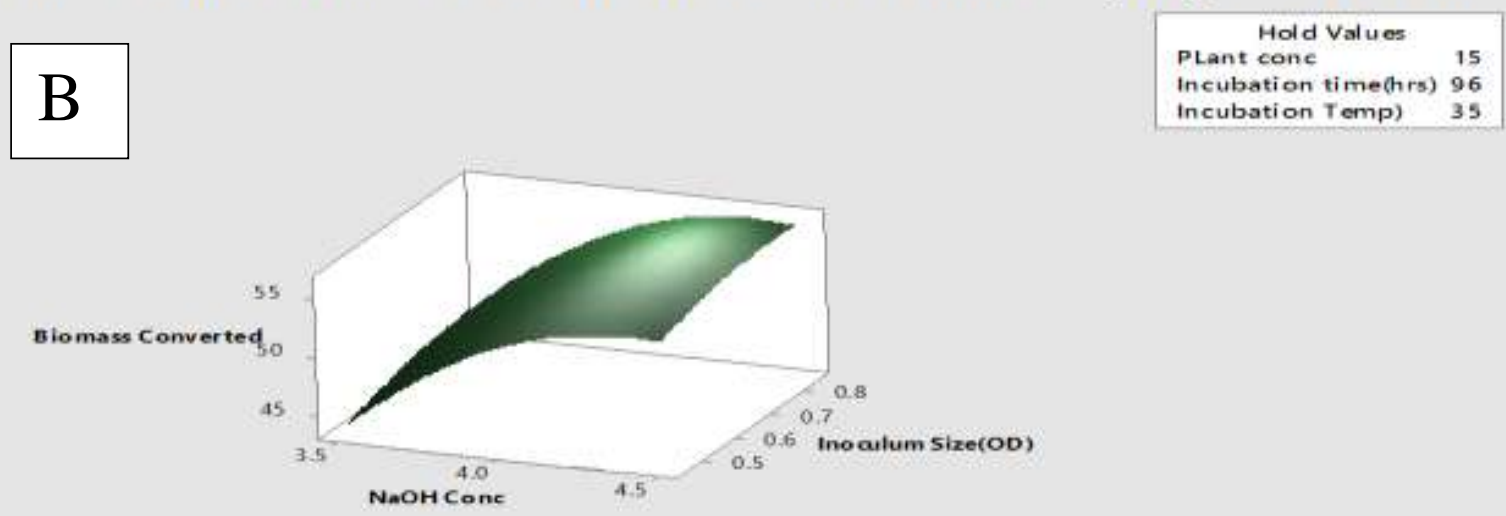

Figure 4b:- Surface Plot of Biomass Converted vs. Size, NAOH Concentration. 


\section{Optimization of factors for the conversion of Biomass to bioethanol.}

Fig. 5a shows the optimization plots for the optimum production of Bioethanol as a function of Brix conversion. The result showed that the optimum conditions for the production of Bioethanol are wood concentration of 15.66g, $\mathrm{NaOH}$ concentration of $4.47 \%$, Inoculum size with an Optical density of 0.85 , Incubation time 72.0 hours and Incubation temperature $40.0 \mathrm{oC}$. At these conditions, the isolate used was able to convert $60.97 \%$ of the Brix in the wood extract to ethanol. Experimentally, at the optimum conditions, a yield of $49.12 \%$ was obtained and the efficiency of the fermentation was calculated as

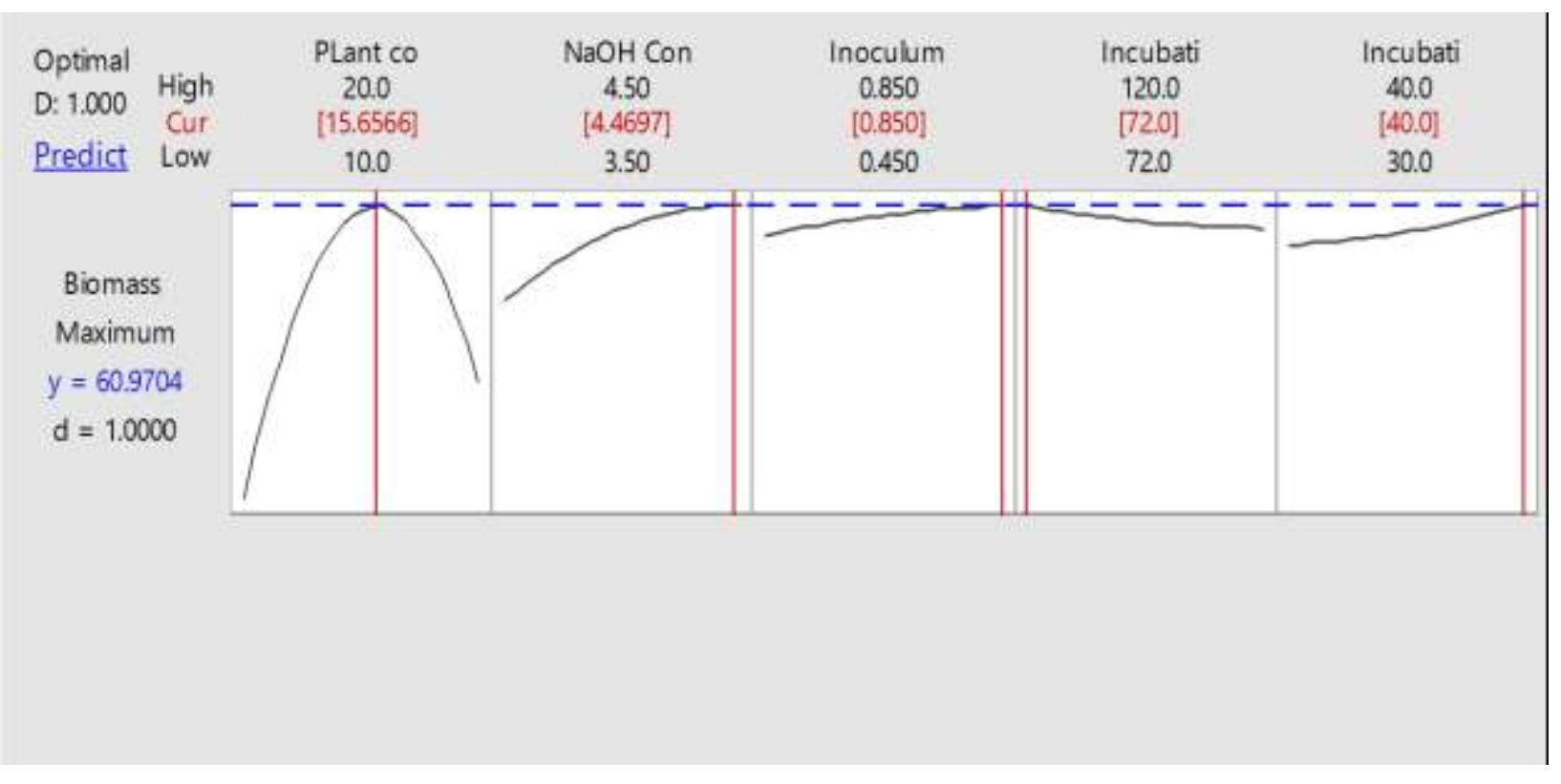

\section{Discussion:-}

During pretreatment process, the biomass is usually depolymerized, washed and the $\mathrm{pH}$ adjusted to 7.0. During this procedure, hydrolyzed sugars are lost and this work aims to utilize the already hydrolyzed sugars that are present, following a chemical pretreatment. This aspect of biomass conversion is poorly explored. The pretreatment is regarded as efficient when the formation of sugars in further enzymatic step of biomass processing is enhanced as well as the degradation of carbohydrates and the formation of inhibitory compounds are limited to minimum(Choi $e t$ al., 2018; Łukajtis et al., 2018; Kumari et al., 2018).

The result obtained from this work showed that the optimum conditions for the production of Bioethanol are wood concentration of $15.66 \mathrm{~g}, \mathrm{NaOH}$ concentration of $4.47 \%$, Inoculum size with an Optical density of 0.85 , Incubation time 72.0 hours and Incubation temperature $40.0 \mathrm{oC}$. Ethanol was calculated from the Brix obtained before pretreatment which gave alcohol yield of 1.96\%, 2.82\% and 3.87\%. After pre-treatment, ethanol was obtained at an optimum time of 72 hours and a yield of $1.68-2.25 \%$ ethanol was produced. The estimated yield is higher when compared to other literatures nevertheless, the result may vary due to the different substrates others used. Braide $e t$ al. (2016) obtained an optimum time of 72 hours and an ethanol yield of 3.45-6.72\% for different substrates obtained from Saccharum officinarum (sugarcane baggasse, sugarcane bark) and maize plant Zea mays (corncob, corn stalk, corn husk). Noura et al. (2014) reported that the isolate, Saccharomyces cerevisiae used in his work had an optimum temperature between 30-40 degrees. Promon et al. (2018) reported an optimum pH of 6 and temperature of $30 \mathrm{oC}$. These data are in agreement with results obtained in this work.

\section{Conclusion:-}

Much energy is trapped in lignocellulosic systems and the need to depolymerize this natural polymer is unending. Truly, bioethanol has promising results and can be used to substitute fossil fuels in the nearest future. In order to encourage zero waste in the production of bioethanol from wood shavings, this work was done using what is regarded as product of chemical pretreatment and used for the production of bioethanol. If energy is lost in this 
process, there is a need to harness this wood extract in the bioethanol production process as a solution for adjusting $\mathrm{pH}$ of the reaction flask rather than discarding it as effluent.

Also, the need for optimization cannot be overemphasized. the optimum conditions for the production of Bioethanol are wood concentration of $15.66 \mathrm{~g}, \mathrm{NaOH}$ concentration of $4.47 \%$, Inoculum size with an Optical density of 0.85 , Incubation time 72.0 hours and Incubation temperature $40.0 \mathrm{oC}$. At these conditions, the isolate used was able to convert $60.97 \%$ of the Brix in the wood extract to ethanol. Alcohol yield was obtained which gave 1.68$2.25 \%$ respectively. Despite the fact that the theoretical yield was not equal to the actual yield, the production of ethanol through the optimized process is vital for production purposes.

\section{References:-}

1. Adeleye, S.A. and Okorondu S. I. (2015). Bioelectricity from Students' Hostel Waste Water using Microbial Fuel Cell. International Journal of biological and Chemical sciences. 9(2):1038-1049.

2. Ajnavi, S. (2008). Department of Biotechnology and Environmental Science. Bioconversion of cellulosic agricultural wastes 69: 1-64.

3. Akaluka, C.K, Orji, J. C. Braide, W., Egbadon, E. O and Adeleye, S. A. (2016). Abattoir wastewater treatment and energy recovery using a Ferricyanide-catholyte Microbial Fuel Cell. International Letters of Natural Sciences. 55: 68-76.

4. APA: Ethanol fuel | Fuel Flow Meter. (n.d). Retrieved from http://www.fuelflowmeter.net/ethanol-fuel/ Chicago: Ethanol fuel | Fuel Flow Meter, http://www.fuelflowmeter.net/ethanol-fuel/ (accessed November 12, 2011)

5. Arland, J. (2002). Biomass to Ethanol: Process Simulation Validation and sensitivity Analysis of a Gasifier and a Bioreactor, p 10-12.

6. Balat, M., Balat, H., and Cahide, O. Z. (2008). Progress in bioethanol processing, Progress in Energy and Combustion Science, 26: 551-573.

7. Bhatia, J. S., Johri. R., and Ahmad. (2012). an economic and ecological perspective of ethanol production from renewable agro waste: A review. Applied microbiology and biotechnology Express. 2: 66-70

8. Biofuels Research Advisory Council (BRAC). (2006). Biofuels in the European Union - A vision for 2030 and beyond: Final draft report.

9. Boullanger, E. (1924). distilleria Agricole et industrielle. Translation from the French by F. Marc de piolen, $\mathrm{p}$. 3-8.

10. Braide, W, Kanu I.A, Oranusi, U.S and Adeleye, S.A. (2016). Production of bioethanol from agricultural waste. J. Fundam. Appl. Sci. 8(2): 372-386. 19

11. Braide, W., Oji, I. N., Adeleye, S. A. and Korie, M. C. (2018). Comparative study of bioethanol production from agricultural wastes by Zymomonas mobilis and Saccharomyces cerevisiae. International journal of Applied Microbiology and Biotechnology Research. 6: 50-60.

12. Brooks, A.A. (2008) Ethanol production potential of local yeast strains isolated from ripe banana peels. African Journal of Biotechnology, 7: 3749-3752.

13. Browning. B.L. (1967). The Chemistry of Wood, Interscience, New York, p. 703.

14. Carere, C.R, Sparling, N., Cicek, D. B., and Levin. (2008). Third generation biofuels via direct cellulose fermentation, International Journal of Molecular Science, 9: 1342-1360.

15. Choi, J.H., Jang, S.K., Kim, J.H., Park, S.Y., Kim, J.C., Jeong, H., Kim, H.Y., and Choi, I.G. (2018) Simultaneous production of glucose, furfural and ethanol organosolv lignin for total utilization of high recalcitrant biomass by organosolv pretreatment. Renewable. Energy 130, 952-960.

16. Dos Santos, M., Borschiver, S., and Couto Maria A. P.G. (2011). "Initiatives for the use of biomass in Ligno Cellulosic Feedstock Biorefineries: the sugar platform in the world and in Brazil". Economy \& Energy, Year XIV-No 82.

17. Egbadon, E.O., Nweke, C.O., Akujobi, C.O., Braide, W., Akaluka, C.K. and Adeleye, S.A. (2016). Bioelectricity Production and Treatment of Abattoir Wastewater in a Ferricyanide catholyte H-type Microbial Fuel Cell. Journal of Biological and Chemical Research. 33 (1): 40-51.

18. Electronic Journal of Biotechnology. (2009). Simultaneous Saccharification and Fermentation process of different cellulosic substrate using a recombinant Saccharomyces cerevisiae harboring the $\beta$-glucosidase gene, vol. 13 no. 2, pp. 1-8.

19. Gnansounou, E.A. and Dauriat, .A. (2005) Ethanol fuel from biomass, Journal of Scientific and Industrial Research, 64: 809-821. 20

20. Harris, E.E., Beglinger, G.J. H., and Sherrard E.C. (1945). "Hydrolysis of Wood: Treatment 
21. Herrera. S. (2006). Industrial biotechnology - A chance at redemption. Nature Biotechnology. 22: 671-675.

22. Huber, G.W., Iborra, S., and Corma, A. (2006). "Synthesis of Transportation Fuels from Biomass: Chemistry, Catalysts, and Engineering". Chemical. Revolution. 106 (9): 4044-98.

23. IEA. (2004). Biofuels for transport: an international perspective. Interview by International Energy Agency, Confidential Industry Source: www.cti2000.it/Bionett/All-2004-004\%.

24. Inderwildi, O.R. (2008). Energy and Environmental Science 2, p. 343.

25. James, E.B., and David, F.O. (1986). Biochemical Engineering Fundamentals Second Edition p. 38-42.

26. Jesper, N. (2005).Ethanol Production from Biomass. Optimization of Simultaneous Saccharification and Fermentation with respect to stirring and heating, p. 1-5.

27. John, W. (2006). Journal on the World watch Institute and center for American progress, Volume \%, p. 30.

28. Joshi, B., and Sreerama, L. (2011). Ligno-cellulosic ethanol production: Current practices and recent developments. Biotechnology and Molecular Biology Review, 6(8): 172-182.

29. Katzen, R., and Schell, D.J. (2006). "Lignocellulosic Feedstock Biorefinery: History and Plant Development for Biomass Hydrolysis". Biorefineries - Industrial Processes and Products, p. 129-137.

30. Kumari, D., Singh, R. (2018). Pretreatment of lignocellulosic wastes for biofuel production: A critical review. Renew. Sustain. Energy Rev. 90, 877-891. 21

31. Lin, Y., and Tanaka, S. (2006). Ethanol fermentation from biomass resources: current state and prospects. Applied Microbiology Biotechnology, 69(6): 627-642.

32. Łukajtis, R., Hołowacz, I., Kucharska, K., Glinka, M., and Rybarczyk, P. (2018). Hydrogen production from biomass using dark fermentation. Renew. Sustain. Energy Rev. 91, 665-694.

33. Lydn, L. R., Wyman, C.E, and Gerngors, T.U. (1999). Bio-commodity engineering. Biotechnology Progress, 15(5): 777-793.

34. Mabee, W.E., Gregg, D.J., Sadler, J.N. (2004). Ethanol from Lignocellulosics: Views to implementation. IEA Task 39 Report T39-P1, 7.

35. Magnus, B. February. (2007). Simultaneous Saccharification and Fermentation of sprue-A comparison of pretreatment condition and different enzyme preparation, p.8.

36. Max, A. (2012).The history of australlian wine: stories from the vineyard to the cella door, carlton, Victoria: victory books, p.79.

37. McCarth, A.J, Peace, E., and Broda, P. (1985). Studies on the extracellular xylanase activity of some thermophilic actinomycetes, Application Microbial Biotechnology, 21: 238-244.

38. Mosier, N. (2005). Features of promising technologies for pretreatment of lignocellulosic biomass. Bioresource Technology, 96(2): 673-686.

39. Noura, E.E., Sahar, D. and Ashraf, K. (2014). Bioethanol Production from Lignocellulosic Feedstocks Based on Enzymatic Hydrolysis: Current Status and Recent Developments. Biotechnology, 13: 1-21.

40. Obileku, P. (2007). "Production of cellulosic ethanol from wood sawdust" Unpublished Bachelor Project work. Department of Agricultural \& Bioresources Engineering, University of Nigeria, Nsukka, Enugu State, Nigeria.

41. Olaniyi, A. A. (2000). Drug quality assurance and pharmaceutical analysis. Ibadan: Mosuro Publishers. 22

42. Paris, M. J, Tavares, C. M. A., and Fonseca L. P. (2014). "Towards Bioethanol: An Overview of Whole Lignocellulose Processing". Research and Reviews in Materials Science and Chemistry, Vol. 4(2): pp. 55-118.

43. Paris. International Energy Agency. (2004). Ethanol from lignocellulosics: views to implementation: Report T39-P1. Task 39. 1

44. Petar, K. (2016). Production and purification of the cellulase enzymatic complex of Trichoderma reesei RutC30. A Phd Thesis submitted to the Department of Chemical Engineering, Instituto Superior Técnico.

45. Promon, S.K, Kamal, W., Rahman, S. (2018). Bioethanol production using vegetable peels medium and the effective role of cellulolytic bacterial (Bacillus subtilis) pre-treatment. F1000 Research 7:271.

46. Raneses, A., Hanson, K., and Shapouri H. (1998). Economic impacts from shifting cropland use from food to fuel biomass bioenergy $\mathrm{p} 15$

47. Rob, P. (2008). Worldwide cellulosic ethanol production in 2020 at least 16.5 billion gallons. www.openpr.com/news/23769/ Ethanol-statistics.html, www.docstoc.com/docs/DownloadDoc.

48. Romaniuk, J. and sharp, B. (2016). How brands grow part 2. Melbourne, oxford university press.

49. Rubaba, I. (2007). An Analysis of producing Ethanol and Electric Power from Residues and Agricultural Crops in east Texas, $\mathrm{p} 27-47$.

50. Shide, E. G., Wuyep, P.A, and Nok, A.J. (2004). Studies on the degradation of wood sawdust by lentinus squarrosulus. (Mont) singer. African Journal of Biotechnology, 3(8): 395-398.

51. Taylor, F., and Francis, P. (2009). Journal of Wood Chemistry and Technology, Volume 30. Bio resourcesEnzyme bases ethanol p 701. 23 
52. Toshiyaki, U. (2007). Chemo-enzymatic production of fuel ethanol from cellulosic material using yeast expressing $\beta$-glucosides. Informit Online. www.springerlink.com/.

53. U.S. Department of Energy Biomass Program. (2013). Theoretical ethanol yield calculator and biomass feedstock composition and property database. http://www.afdc.energy.gov/fuels/ ethanol_feedstocks.html (accessed June 29, 2013).

54. Wikipedia. (2011) Cellulose ethanol commercialization Accessed. From http://en.wikipedia.org/wiki/Cellulosic_ethanol with Sulfuric Acid in a stationary digester" Industrial and Engineering Chemistry, 37(1): 12-23.

55. Wyman, C. (2012). Opportunities and technological challenges of bioethanol, Presentation to the Committee to Review the R\&D strategy. For Biomass-Derived Ethanol and Biodiesel Transportation Fuels, 1999, Irvine, California: Beckman Center. 